\title{
Challenges in managing infrastructure for urban tourism: a comparative study of three Asian cities
}

\author{
J. Jamil \& M. S. Puad \\ School of Housing, Building \& Planning, Universiti Sains Malaysia, \\ Malaysia
}

\begin{abstract}
There has been tremendous competition between Asian countries in promoting their tourism sector since the economic crashes of 1986 and 1997. Terrorism, which haunts Western nations, has spread to Asian countries. This greatly affects the notion held by the world at large of Asia as the 'Worlds Paradise'. As such, the level of competition between neighboring countries in the ASEAN block of nations, such as Indonesia, Thailand, Vietnam, Philippines, Singapore, Cambodia and Malaysia, has increased.

Investments in tourism related infrastructures are important in generating tourist arrivals. It not only provides enough infrastructures, but also has to make sure that it is first class infrastructure for tourist satisfaction. In the situation on the factor of provision cost, high demand from the consumer, suitability of the location and the efficient management of the operator are the important aspects needed for action to be taken by the infrastructure executive agency. The effective infrastructure contributes to the best service and affects the growth of our local tourism sector. This paper will present how and how far cities in the ASEAN have to take action towards the infrastructure management council and the impact towards the tourism factor in their countries. Are there any ways and strategies in managing and maintaining infrastructure to sustain the city tourism? Keywords: infrastructure, management, tourism, sustain.
\end{abstract}




\section{Introduction}

The tourism industry is the second main sector in Malaysia. The government spent RM330m in 2005 in developing this sector. Island tourism is the favored choice by the European and American tourists. However, the increase of the infrastructure and service facility in the city has encouraged city tourism to be the second choice after tourism based on nature and eco-tourism. The emerging tourists from Asia, such as those from Korea, Japan, East Asia, West Asia, Taiwan and China, spell opportunity to the tourism sectors in South East Asia, especially the ASEAN countries, such as Indonesia, Cambodia, Thailand and Malaysia. Infrastructure development and public amenities in various economic sectors help the growth of the tourism sector. The provision of a number of city facilities, physical infrastructure, service and management shows status of the city or tourism destination in the country/city [1]. Malaysia has the best infrastructure in South East Asia and cities of Georgetown, Kuala Lumpur, Malacca and Johor Baharu have first class infrastructure. Not less than that, tourism islands in Malaysia, such as Langkawi, Tioman and Redang, have always had a large allocation to develop the infrastructure. Similarly, as in the cities and the tourism destinations in Malaysia, it is the tourism sector that supports the provision of the infrastructures and sophisticated services in the region.

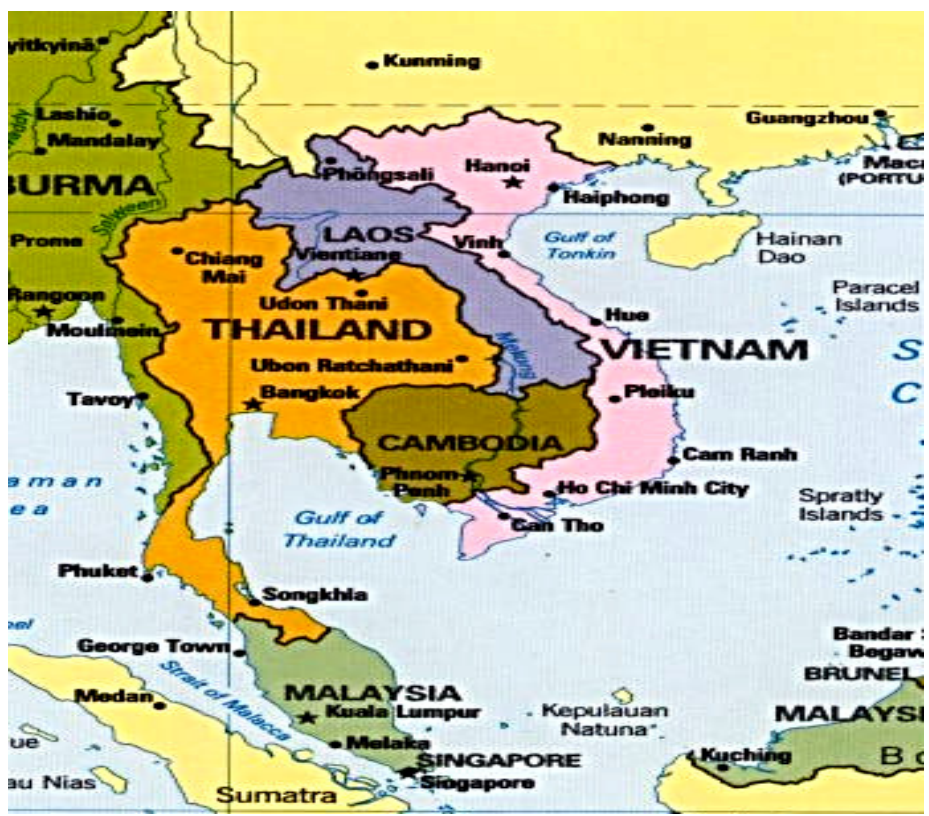

Figure 1: Map of the South East Asian region. 


\section{Study issue}

Infrastructure and services in the tourism sector in cities in Malaysia is the best in South East Asia, but somehow the number of foreign tourists is still low when compared to the other four ASEAN countries (Thailand, Cambodia, Singapore and Indonesia). Georgetown, formerly famous as 'Hong Kong Malaysia' but now the Penang Road, has barely any visitors in the evening. Kuala Lumpur somehow still sustains its sector with the commercial center and Langkawi can attract domestic tourists during school holidays and celebrations. These three locations are destinations that provide the best and most sophisticated facilities in Malaysia, even in the ASEAN. Even though the journey from the Phnom Penh to Angkor Watt takes more than six hours through 60 feet width 'highway', it attracts the arrival of tourist at a rate of more than 500 visitors per hour. The difference indicators, such as images, fame, services, suitability and originality, are the determining factors that could attract foreign tourists to visit the tourism destination.

Could this statement prove to be accurate by fact and information, rationale and responsibility?

\section{Significant issues}

The competition in the international market today will soon be more competitive, especially between the neighborhood countries, such as Singapore, Thailand, Indonesia and the Philippines, which have the same tourism product as Malaysia. The existence of the tourism countries, such as Vietnam, Myanmar and Cambodia, not only provides interesting and competitive tourism products, but also offers cheaper services and has romantic and mysterious destinations that give stiff competitive [2].

a) Images from several cities in the ASEAN, as tourism destinations, are not as obvious compared to other destinations in other countries, such as Paris, London, Beijing, Sydney, New Delhi, Cairo, and Rome. The support provision infrastructures in those countries are obviously sophisticated.

b) Weather, safety, culture and season are the factors influencing the tourist trend movement in Malaysia and South East Asia. Due to this issue, during the (monsoon) raining season the tourist alternative will be to concentrate on the tourism cities. The capacity to provide the best infrastructure and service in the city to the foreign tourists gives challenges to the administration and management of the city.

c) How far the cities in the ASEAN could be pursued as the destination of tourism cities and how could this be sustained so that it is comparable to the destination in other countries?

d) Do originality and image of the tourism product in ASEAN cities satisfy the tourist demand? Efficiency in infrastructure facility and the 
satisfaction in terms of need and expectation, however, are the main factors that attract foreign tourists.

e) Malaysia's neighboring countries, namely Thailand, Indonesia and Cambodia, have the 'Wonder of the World' destinations, such as Angkor Watt, Menam Chao Phraya and Danao Toba. Are there any attractive elements available in Langkawi or other islands in Malaysia?

\section{Study requirements}

1. To identify the existing scenario of infrastructure and facility management system in three ASEAN cities and to explore the change in trend of products these cities offered. Analysis on the suitability of the infrastructure and facility management system to support the industry is also being carried out.

2. To identify the role of infrastructure in ASEAN cities and how it could help to increase the arrival of local and foreign tourists.

3. To analyze the direction of managing ASEAN cities and to clarify whether the cities could compete themselves and their position be sustained with other European cities.

\section{Research scope}

Research involved three countries, Thailand, Cambodia and Malaysia, and the cities involved are Bangkok, Phnom Penh and Georgetown.

\subsection{Phnom Penh}

Phnom Penh is located in the south-central region of Cambodia, at the confluence of the Tonlé Sap, Mekong, and Bassac rivers. Administratively, Phnom Penh is a municipality standing at 375 square kilometers and is governed with a status that is equal to the provinces of Cambodia. The municipality is subdivided into seven administrative divisions called Khans (districts). All Khans are under the governance of the Phnom Penh Municipality, which is further subdivided into 76 Sangkats (communities), and 637 Kroms (villages) [3].

The municipality is governed by the Governor, who acts as the top executive of the city and manages the general affairs as well as overlooking 27 Administrative Departments. As of 2008, Phnom Penh had a population of $1,325,681$ people, with a total population density of 4,571 inhabitants per square kilometer $(11,839 / \mathrm{sq} \mathrm{mi})$ in a $290 \mathrm{~km}^{2}(112 \mathrm{sq} \mathrm{mi})$ city area. Annual population growth in the city over the period $1998-2008$ is $2.82 \%$ [4].

\subsection{Bangkok}

The city of Bangkok is the capital, largest urban area and primary city of Thailand. It has its own public administration and governor. In the span of over 
two hundred years, Bangkok has been the political, social and economic center of not only Thailand, but also for much of South East Asia and Indochina as well. Its influence in the arts, politics, fashion, education and entertainment, as well as being a business, financial and cultural center of Asia has given Bangkok the role of global city. It is the world's 22 nd largest city by population with approximately 15 million people [5], with a vibrant mix of Western, Indian and Chinese people. The capital is part of the heavily urbanized triangle of the central and eastern region of Thailand.

Bangkok is subdivided into 50 districts (khet or amphoe), which are further subdivided into 154 kwaeng (or tambon). Each district is managed by a district chief appointed by the governor. There is also an elected Bangkok Metropolitan Council, which has power over municipal ordinances and the city's budget. The government of Bangkok is called the Bangkok Metropolitan Administration or the BMA.

\subsection{Georgetown}

Georgetown was founded in 1786 by Captain Francis Light, a trader for the British East India Company, as a base for the company in the Malay States. The town was built on swampy land that had to be cleared of vegetation, leveled and filled. The original commercial town was laid out between Light Street, Beach Street, Chulia Street and Masjid Kapitan Keling Street.

Due to strict rent controls, Georgetown retains many of its colonial-era shophouses to this day and is often considered an architectural gem. Since the repeal of the rent controls in 2000, many pre-war buildings have given way to new high rises. On 7 July 2008, Georgetown was, together with Malacca, formally inscribed as a UNESCO World Heritage Site. It is officially recognized as having a unique architectural and cultural townscape without parallel anywhere in East and Southeast Asia [6]. Georgetown, Penang, has more than 200 years of urban history and the largest collection of heritage shop houses in Southeast Asia. Upon examination of records on property transaction, rent-control records, development applications and demographic trends, no conclusive evidence was found that this Act was instrumental in protecting heritage buildings. Instead, it was the unintentional effects of various development policies that saved Georgetown's urban heritage [7]. The tourism industry in Penang was badly affected by the tsunami tragedy in terms of hotel occupancy rates, tourist arrivals and the performance of tourism related businesses during the first quarter of 2005. However, signs of recovery have been observed from January to September 2005 [8].

\section{Research method}

A continuous inventory and visual analysis have been started since June 2003 with regards to the changes and trend of infrastructure management on those three ASEAN cities; however, an in-depth study was started in June 2006. The aspects of analysis involved were: 


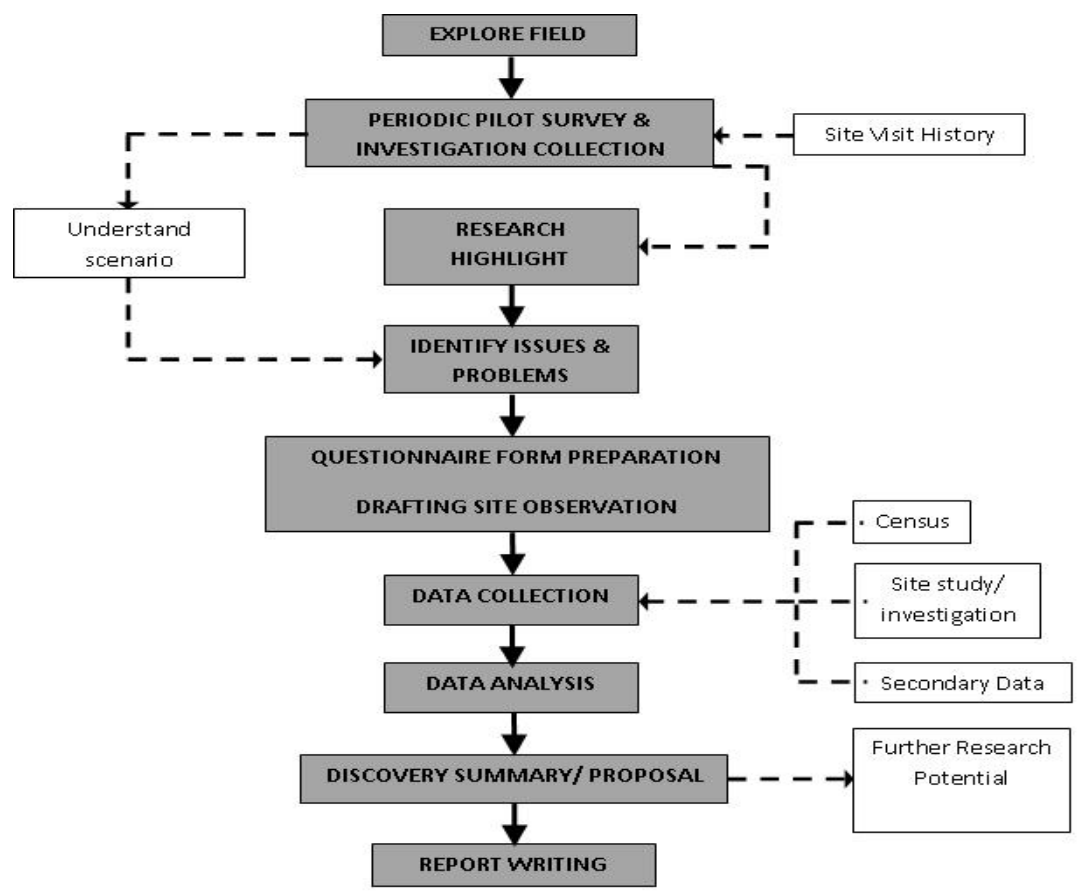

Figure 2: $\quad$ Research method.

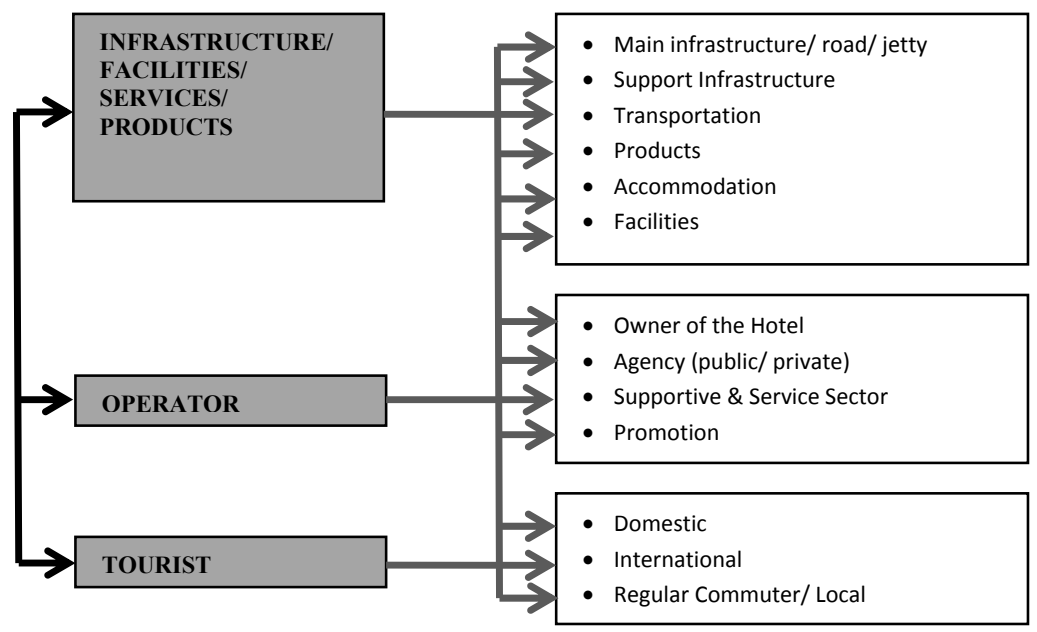

Figure 3: $\quad$ Research focus. 
a) History and heritage of the cities.

b) Urban design, architecture, land use planning and economic activities.

c) Infrastructure facilities and services provided in the cities, inter cities and tourism destinations and the support facilities.

d) Operation methods, management and maintenance of the infrastructure facilities by the executive agency and the operator.

e) Relation between the infrastructure facilities with the city/rural tourism destination from the perspectives of service, comfort, safety, time and cost to the tourist.

The questionnaire method, conservation by trends, secondary information checks and field census will be conducted during the study.

Study duration: June 2006-Feb 2008.

\section{Research focus}

The research focuses on three components in the tourism sector, they are: tourist, tourism operator and product and tourism facilities.

\section{Research findings}

\subsection{Malaysia's role towards developing the tourism infrastructure}

a) Infrastructure and Nature

Tourism infrastructure supports the creation of community facilities and services that otherwise might not have been developed. It can bring higher living standards to a destination. Benefits can include upgraded infrastructure, health and transport improvements, new sports and recreational facilities, restaurants, and public spaces, as well as an influx of better-quality commodities and food [9]. Tourism base needs in developing the facilities and infrastructure have emphasis more in cushioning to the environment. Besides tightening the existing rules in conjunction of protecting nature, rules and regulations and specific criteria are being enacted to ensure infrastructure development for tourism does not affect the sensitive tourism surroundings, such as rivers, seashores and beaches. At the same time, there are efforts by the government to identify new tourism products based on nature and journey interest, especially in the tourism context based on agriculture and ecology.

b) Air Transportation

The growth of air transportation that was underway contributed to the development of the tourism industry. The spread of local airways have prescribed the fixed cost, which is affordable and offers the best service to the consumer, and will encourage the arrival of the tourist, especially from the major market countries and potential new markets. The 
operation of low-cost carrier Air Asia and Fire Fly have triggered encouraging growth of tourists' travel, domestically and internationally.

c) Land Transportation

The growth of the tourism industry was encouraged by the development of the various modes of transportation. The construction of the highway and new main roads encourages people to drive during their holiday and facilitates public transport inter the main city and resort. It is expected that the private sector will be encouraged to invest in new vehicles and efficient machinery and tools that give services to the growth of this industry. In the city of Georgetown alone, there are approximately 600 taxi operators that provide private transportation services and they have to compete with public transportation services, such as buses and trishaws and other modes of transportation.

d) Upgrading the Rest \& Retreat Facility (R\&R)

The government and private sector had been developing a sophisticated and modern R\&R area. The North South Highway Corporation has provided a R\&R every $600 \mathrm{~km}$ along the highway and is very effective and gives positive impacts for the domestic tourist and the long distance traveler. A study found that in the holiday season, school holidays and during weekends, more than $30 \%$ of users utilize the R\&R. That means the demand of the $R \& R$ is exceeding the offer limit.

e) Train Service

To encourage tourists to use trains as one of the transportation modes, Keretapi Tanah Melayu Berhad (KTMB) has improved the itinerary and the service quality. Varieties of travelling packages for users, such as students, families, agencies, individuals and foreign tourists, have been prepared. Long distance travel to Bangkok from Johor Baharu, Kuala Lumpur and Penang give alternatives to the tourist who prefers land transportation because of the safety, comfort and lack of time-pressure.

\subsection{Comparative study}

a) Function and land use activity: Travel and tourism normally promote substantial investments in new infrastructure, most of which help to develop the living conditions of the host country as well as the stay conditions of tourists [10]. The optimum urban space usage was found to be more economic, even though there is no detailed planning in Phnom Penh. This involves building and land space, and space utilization according to need and market. Almost $70 \%$ of the city areas are fulfilled by the commercial activities that attract tourists because of the cheap goods cost. Even though Georgetown is one of the oldest cities in Malaysia, various changes have been implemented towards the progression of the city through the Structure Plan Program until 2010, yet the city's heritage is not threatened by it. 

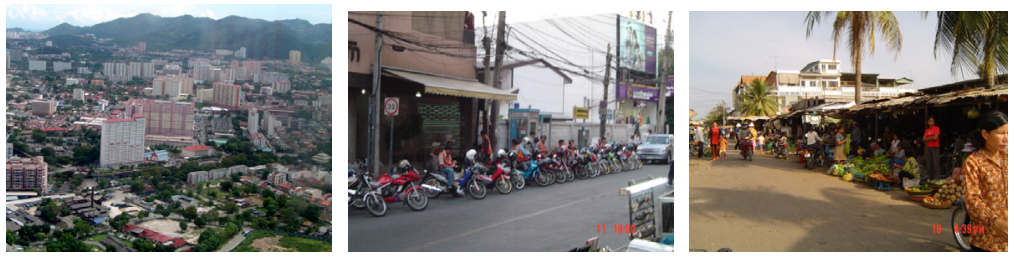

Figure 4: $\quad$ Land use activities in Georgetown, Bangkok and Phnom Penh.
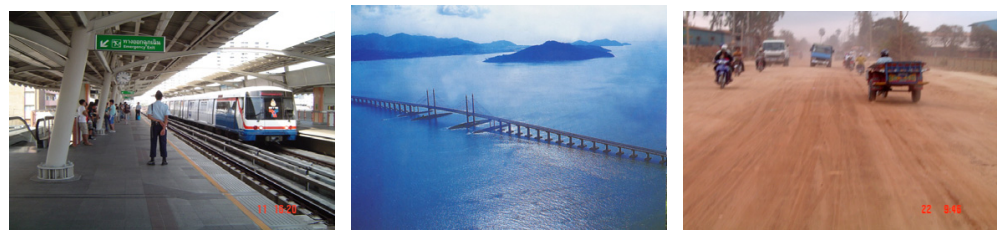

Figure 5: Different standards of infrastructure for the three cities.

b) City facilities and services: This represents the image of the city, which provides first class, second class or lowest standard facilities. It also shows the urban community image. Bangkok itself shows its own urban image based on the concepts of religion, culture and lifestyle. The various modes of transportation found in the city of Bangkok have made travel easy for tourists, allowing them to arrive at their destinations in a safe and timely manner. The standard of facilities shows the urban image (this often happens with the unsystematic urban spaces). As mentioned by Mathieson and Wall [11], the number of roads and vehicles in Los Angeles exceeded the tourism infrastructure in the city and surrounding areas. Due to this fact, as can be studied in Georgetown, the excess provision of infrastructure not only adds to city congestion, but it also adds to the complexity in management.

c) Facilities and urban service management: Urban management gives impacts to generating urban economic activity, community activities and urban image. Georgetown and Bangkok would be able to provide the first class facilities starting from roads, street furniture and the public urban facilities. Phnom Penh, however, provides the basic urban facilities that have been provided by Georgetown and Bangkok in the last two decades. Basically, 90\% of the roads and streets of Penang and Georgetown are of the standard equivalent to other rich cities, such as Tokyo, Seoul and Shanghai.

d) Building form and structure: This is the influence and history element; religion and lifestyle gives an impact to the architecture of the buildings. The pressure from current market demands is to demolish heritage buildings and artistic worth and build new buildings with function and economic values. Cities in Asia still 
can sustain their building like European countries. Historical and heritage buildings in Georgetown and Bangkok have still been sustained until now. In Phnom Penh, buildings and hotels still retain the French architecture portion, at the very least in the façades and rooftops.

e) Freedom of movement, activities, form and color shows the image of the cities. An economic activity is managed by the structure and layout of the city. Carrying capacity can be said to be the maximum number of people who can use a destination without an unacceptable change taking place. Attracting a large number of visitors is not an end in itself [12]. Circulation and movement of the urban community and tourists are influenced by the building layout, architecture, history and culture, uniqueness and originality of the architecture, access to facilities, safety and comfort. The facilities and attractive products are used to generate the arrival of tourists and encourage them to continue their visit to the city.

f) Some highlights from the result of the comparative study are discussed in the conclusion below.

\section{Conclusion}

Rhythm, rules, community movement and activities are influenced by the layout of the buildings, activities and municipal function. The efficient management through infrastructure and city facilities provides opportunities for visitors to involve themselves in the tourism activities. In ASEAN cities, the management of Phnom Penh and Hanoi are apparently different compared to the management of Kuala Lumpur, Georgetown and Bangkok, which have been declared as destinations that have the best infrastructure in Asia. However, the arrival of foreign tourists to Phnom Penh and Hanoi are increasing and competing with the established cities. This has proved that destination that give satisfaction and attraction are given more priority by tourists. Almost $70 \%$ of the areas in Georgetown, Bangkok and Phnom Penh are commercial areas, where only Georgetown and Bangkok could still sustain the heritage city status, following the UNESCO requirement and guidelines. Bangkok could portray its own image as a tourist city compared to Georgetown and Phnom Penh, which reflects the
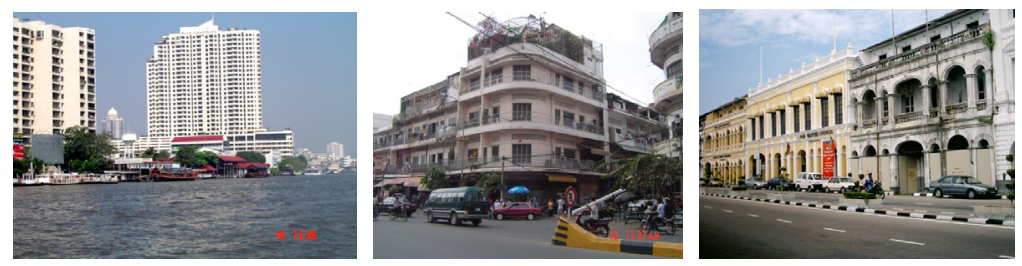

Figure 6: The design concept of buildings in Bangkok, Phnom Penh and Georgetown. 
colonial architecture for its building and infrastructure. The provision and maintenance of urban infrastructure in Bangkok and Georgetown follows the standard planning guidelines (ACT 172: Town \& Country Planning Act 1995, as for Malaysia), whereas basic requirement infrastructure provision has been imposed in Phnom Penh. Gazette planning and building by-laws, the Urban Structure Plan 2020 and the National Urbanization Policy 2008 are some of the strategies taken by Georgetown City Council and Bangkok Metropolitan Authority to plan, control and manage their urban infrastructure in sustaining a successful urban tourism industry.

\section{References}

[1] Nangia, R. R. Cross Border Infrastructure in Market Economy, 12-24 Mac 2006. Economic and Finance Institute, Phnom Penh, Cambodia.

[2] Ness, D. Smart, sufficient and sustainable infrastructure systems, UN Expert Group Meeting Bangkok, 11-13 June 2007. Institute for Sustainable Systems and Technologies/School of Natural and Built Environments, University of South Australia, May 2007.

[3] Phnom Penh (last modified on 3 September 2009). Wikipedia Online. http://en.wikipedia.org/wiki/Phnom_Penh (Assessed online: 28 October 2009)

[4] H.E. Kep Chuk Tema, Governor of Municipality of Phnom Penh. Speech at the Inauguration of Gate Way and Park, the North of Wat Phnom, March 22, 2007.http://www.phnompenh.gov.kh/english/2007/March/March-222007a.html

[5] Bangkok (last modified on 14 September 2009). Wikipedia Online. http://en.wikipedia.org/wiki/Bangkok (Assessed online: 7 October 2009)

[6] George Town, Penang (last modified on 27 July 2009). Wikipedia Online. http://en.wikipedia.org/wiki/George_Town,_Penang (Assessed online: 2 October 2009)

[7] Lee L.M. Politics and performance: the implications of emerging governance arrangements for urban management approaches and information systems. Habitat International, 32(3), pp. 293-304, 2008.

[8] Penang Progress Report (2007). Visitor Arrivals to Penang. Tourism Malaysia, Penang, 2007

[9] Doswell, R. Tourism: How Effective Management Makes the Difference, Oxford, Boston, Butterworth-Heinemann. 1997.

[10] Bull, P. Tourism in London: Policy changes and planning problems, Regional Studies. pp. 82-85, 1997.

[11] Mathieson, A., \& Wall, G. Tourism: Economic, physical and Social Impacts, New York: Longman Scientific \& Technical. 1982.

[12] Mason, P. Tourism Impacts, Planning and Management. Oxford, Butterworth-Heinemann (Elsevier), pp. 196, 2003. 